\title{
Enhancement of Polyphenol Content and Antioxidant Activity of Brown Alga Eisenia bicyclis Extract by Microbial Fermentation
}

\author{
Sung-Hwan Eom ${ }^{1}$, Young-Mi Kang ${ }^{2}$, Jae-Hong Park ${ }^{1}$, Dae-Ung Yu ${ }^{1}$, Eun-Tak Jeong ${ }^{3}$, Myung-Suk Lee ${ }^{4}$ and \\ Young-Mog Kim ${ }^{1 *}$ \\ ${ }^{1}$ Department of Food Science and Technology, Pukyong National University, Busan 608-737, Korea \\ ${ }^{2}$ Marinebioprocess Co., Ltd., Busan 619-912, Korea \\ ${ }^{3}$ SNTECH Co., Ltd., Seongnam 463-760, Korea \\ ${ }^{4}$ Department of Microbiology, Pukyong National University, Busan 608-737, Korea
}

\begin{abstract}
The objective of this study was to select an effective microbial strain to improve the functional qualities of Eisenia bicyclis water extract by fermentation. For this purpose, several microorganisms isolated from traditional Korean fermented foods were inoculated and cultivated in E. bicyclis water extract. Ultimately, yeast strain YM-1 was selected for further study based on its total phenolic compound (TP) content and antioxidant activity, which were enhanced by microbial fermentation. The extract fermented by YM-1 exhibited a superior TP content and 2,2'-diphenyl-1-picrylhydrazyl (DPPH) radical scavenging activity compared to extracts fermented by other microbes. The highest TP content and DPPH radical scavenging activity were observed after one day of YM-1 fermentation. Yeast strain YM-1 was identified as Candida utilis based on an analysis of its physiological characteristics. During fermentation of the extract by C. utilis YM-1, no significant difference was observed in the proximate composition, including moisture, crude lipid, crude protein, and crude ash. Fermentation by C. utilis YM-1 resulted in enhanced biological activity, including increases in the TP content and antioxidant activity. Thus, fermentation by $C$. utilis YM-1 is an attractive strategy for developing value-added food ingredients.
\end{abstract}

Key words: Antioxidant activity, Candida utilis, Eisenia bicyclis, Fermentation, Phenolic compound

\section{Introduction}

Seaweeds are rich in minerals and dietary fiber and are thus typically used as a health food. One such seaweed, Eisenia bicyclis (Kijellman), is used in various dishes including appetizers, casseroles, muffins, pilafs, and soups (Maegawa, 1990). Eisenia bicyclis was previously reported to be a potent source of bioactive phenolic compounds known as phlorotannins. Phlorotannins with antioxidant activity isolated from $E$. bicyclis include eckol (a trimer), phlorofucofuroeckol A (a pentamer), dieckol (a hexamer), and 8,8'-bieckol (a hexamer) (Okada et al., 2004). The biological activities of this brown algae have also shown activities against tumors (Noda et al.,
1989), Alzheimer's disease (Jung et al., 2010), inflammatory diseases (Shibata et al., 2003), and allergic diseases (Shibata et al., 2002). Despite its key biological activities, E. bicyclis has largely been used raw, frozen, or salted in processed products and in products that confer none of the advantages of highly processed seaweeds (Heo and Jeon, 2005). The development of processed foods containing seaweeds is necessary to attract consumers and enhance seaweed consumption (Bae and Kim, 2010; Eom et al., 2010; Song et al., 2011b).

Fermentation by living beneficial microorganisms may be useful in achieving this goal. Generally speaking, fermenta-
Open Access http://dx.doi.org/10.5657/FAS.2011.0192

This is an Open Access article distributed under the terms of the Creative Commons Attribution Non-Commercial License (http://creativecommons. org/licenses/by-nc/3.0/) which permits unrestricted non-commercial use, distribution, and reproduction in any medium, provided the original work is properly cited. pISSN: 2234-1749 eISSN: 2234-1757
Received 27 July 2011; Revised 29 July 2011; Accepted 10 August 2011

*Corresponding Author

E-mail: ymkim@pknu.ac.kr 
tion is a biochemical reaction that metabolizes high-molecular weight organic compounds into simpler molecules. Fermentation not only enhances the nutrient content of foods through the biosynthesis of vitamins, essential amino acids, and proteins, it also improves protein quality and fiber digestibility. Furthermore, fermentation improves micronutrient bioavailability and aids in the degradation of anti-nutritional factors (Achinewhu et al., 1998; Adewusi et al., 1999; Bae and Kim, 2010). Here, we report a microbial strain that effectively improved the functional qualities of E. bicyclis water extract and describe the physiochemical and nutritional changes that occurred in the extract as a result of microbial fermentation.

\section{Materials and Methods}

\section{Plant materials and sample preparation}

E. bicyclis was collected on Ulleung Island, Korea, in September 2010. As described previously, the sample was rinsed with fresh water to eliminate foreign materials such as sand and shells (Song et al., 2011b). Next, the sample was desalinated by soaking two to three times in two volumes of water for $1 \mathrm{~h}$ each. The desalinized sample was cut into an efficient size for extraction using a grinding mill. To prepare a water extract of E. bicyclis, 20 volumes of water were added, and the mixture was autoclaved and then centrifuged to remove all $E$. bicyclis residue. After cooling at room temperature, the extract was stored at $-70^{\circ} \mathrm{C}$ until use.

\section{Microbial strains and selection of a strain for fermentation}

The microbial strains used in this study were isolated from traditional Korean fermented foods and maintained at the Food Microbiology Laboratory, Department of Food Science and Technology, Pukyong National University. Selection of a strain for fermentation was done by assaying the total phenolic compound (TP) content and antioxidant activity during fermentation of the E. bicyclis extract. The following strains were tested: three Lactobacillus strains (LB-1, -2, and -3) isolated from kimchi by enrichment culture using MRS broth (Difco, Detroit, MI, USA), two Bacillus strains (BC-1 and -2) isolated from meju using Mannitol Egg Yolk Polymyxine Agar (Oxoid Ltd., Hampshire, UK), and three yeast strains (YM-1, -2, and -3) isolated from meju using YM broth (Difco). Fermentation was conducted in a flask containing $500 \mathrm{~mL}$ of the extract that had been inoculated with $10 \%(\mathrm{v} / \mathrm{v})$ fresh culture. The samples were incubated aerobically with agitation $(120 \mathrm{rpm})$ at $30^{\circ} \mathrm{C}$. Sampling was done at regular intervals (Bae and Kim, 2010).

\section{Analysis of the TP content}

The TP content was determined according to a modified version of the Folin-Ciocalteu method using phloroglucinol as the standard (Kim et al., 2006a; Bae and Kim, 2010). The samples were diluted to match the measurable range of the spectrophotometer. A $0.1 \mathrm{~mL}$ aliquot of the diluted sample was mixed in an Eppendorf tube with $0.5 \mathrm{~mL}$ of $1 \mathrm{~N}$ FolinCiocalteu reagent. The mixture was allowed to stand for $3 \mathrm{~min}$ following the addition of $0.4 \mathrm{~mL}$ of $20 \% \mathrm{Na}_{2} \mathrm{CO}_{3}$. The samples were incubated in the dark at room temperature for $45 \mathrm{~min}$ and then centrifuged at $1,600 \mathrm{~g}$ for $8 \mathrm{~min}$. The optical density of the supernatant was measured spectrophotometrically with a GENios ${ }^{\circledR}$ microplate reader (Tecan Austria GmbH, Grödig, Austria) at $765 \mathrm{~nm}$. The TP content (\%) was calculated using a standard graph. The TP content in the non-fermented or fermented extract was calculated using the following linear equation based on the calibration curve:

$$
\mathrm{Y}=0.5337 \mathrm{X}+0.3615, r^{2}=0.9874
$$

where, $\mathrm{Y}$ is the absorbance and $\mathrm{X}$ is the total phenolic contents in milligram phloroglucinol equivalents per gram extract.

\section{Physiological identification of the isolated yeast strain}

According to the manufacturer's instructions, portions of each yeast strain were picked up with a sterile loop from the YM plates and then suspended in API basal medium ampoules (Gündeş et al., 2001). The suspensions were used to fill the cupules of the test strip (API 20C AUX system; bioMérieux, Marcy l'Étoile, France). The API trays were inoculated and incubated for $72 \mathrm{~h}$ at $30^{\circ} \mathrm{C}$. The growth in each well was recorded after 24, 48, and $72 \mathrm{~h}$ of incubation. A profile number based on the reactions was assigned and identifications were made by reference to the API Analytical Profile Index (bioMérieux). Cupules showing turbidity that was significantly greater than that in the negative control cupules were considered positive (Fenn et al., 1994).

\section{Analysis of the proximate composition, $\mathrm{pH}$, and salinity}

Filtered extracts were analyzed for $\mathrm{pH}$, salinity, and proximate composition. The moisture content was measured by oven-drying at $105^{\circ} \mathrm{C}$ to a constant weight. The contents of crude ash, crude protein, and crude lipid were determined by standard methods (Association of Official Analytical Chemicals, 1995). Reducing sugars were measured by the Somogy method with a minor modification (Somogyi, 1952). All experiments were carried out in triplicate. The data are shown as mean values.

The $\mathrm{pH}$ was measured with a tip probe electrode. Salinity was measured by converting the chlorine content into sodium chloride using a YSI $63 \mathrm{pH}$ meter (YSI Inc., Yellow Springs, $\mathrm{OH}, \mathrm{USA})$. 


\section{Analysis of free amino acids (FAAs)}

The determination of FAAs was done by ion-exchange chromatography using a Hitachi model L-8900 amino acid analyzer (Hitachi Co. Ltd., Tokyo, Japan) with methods adapted from the literature. A total of $10 \mu \mathrm{L}$ of supernatant filtered through a $0.45-\mu \mathrm{m}$ syringe filter (Advantec, Tokyo, Japan) was applied to an ion exchange column (\#2622SC; Hitachi Co. Ltd.) using lithium citrate buffer.

\section{2,2'-Diphenyl-1-picrylhydrazyl (DPPH) radical scavenging activity}

DPPH radical scavenging activity was measured as described by Qureshi et al. (2010). A total of $1 \mathrm{~mL}$ of non-fermented or fermented extract (diluted 100-fold) was added to $1 \mathrm{~mL}$ of $0.2 \mathrm{mM}$ DPPH in ethanol. After mixing vigorously for $30 \mathrm{~s}$, the solution was incubated at $37^{\circ} \mathrm{C}$ for $30 \mathrm{~min}$. The DPPH radical scavenging activity of the solution was measured using a GENios ${ }^{\circledR}$ microplate reader (Tecan Austria $\mathrm{GmbH}$ ) at $517 \mathrm{~nm}$. The DPPH radical scavenging activity was calculated using the following equation, in which $H$ and $H_{0}$ are the relative peak height of radical signals with and without sample, respectively:

$$
\text { Radical scavenging activity }=1-\frac{H}{H_{0}} \times 10
$$

\section{Results and Discussion}

\section{Change in the TP content and DPPH radical scav- enging activity by microbial fermentation}

Seaweeds possess metabolites with useful biological activi- ties, including antifungal, antioxidant, antiviral, and antitumor activities (Noda et al., 1989; Nagayama et al., 2002; Kim et al., 2006b). It was previously reported that a seaweed extract containing commercial enzymes showed enhanced antioxidant (Heo et al., 2005) and anticoagulant activities (Athukorala et al., 2006). However, such enzymes are expensive. Therefore, our laboratory has focused on the microbial fermentation of seaweeds as an alternative method (Bae and Kim, 2010; Eom et al., 2010; Song et al., 2011b). The biological activities of plant materials have been reported to relate to their content of phenolic compounds (Lee et al., 2009), and these activities are based on the physiological functionalities of polymers of polyphenol (McDougall et al., 2005). In this study, we used an increase in TP content to judge the effectiveness of microbial fermentation. The change in antioxidant activity during fermentation of the extract was monitored as an indicator of the biological activity of the sample.

As shown in Table 1, the TP content of the E. bicyclis extract was enhanced by fermentation using all of the microbes tested compared to the control (unfermented extract). The highest TP content (47.5 mg phloroglucinol equivalents [PGE]/g) was observed after one day of fermentation with YM-1, followed by the Lactobacillus sp. BS-1 extract ( $44.7 \mathrm{mg}$ PGE/g) on 5 days of microbial fermentation. These results are consistent with previous data showing that Lactobacillus fermentation of a Hizikia fusiforme extract and fungal fermentation of a Laminaria japonica extract enhanced the TP content (Bae and Kim, 2010; Song et al., 2011a, 2011b). We suspect that the rise in TP content resulted from the fermentation-enhanced breakdown of plant cell walls by various enzymes.

Polyphenolic compounds are known to possess antioxidant activity (Jiménez-Escrig et al., 2001). We measured the antioxidant activity of the extract before and after microbial fermentation. As shown in Fig. 1, the DPPH radical scavenging activity rose as the TP content of the E. bicyclis extract

Table 1. Change of total phenolic contents in Eisenia bicyclis water extract by microbial fermentation

\begin{tabular}{lcccc}
\hline \multicolumn{1}{c}{ Sample } & \multicolumn{4}{c}{ Total phenolic content (PGE $^{*} \mathbf{~ m g} / \mathbf{g}$ of dry weight) } \\
\cline { 2 - 5 } & $\mathbf{0}$ day & $\mathbf{1}$ day & $\mathbf{3}$ day & $\mathbf{5}$ day \\
\hline Control $^{\dagger}$ & $36.11 \pm 0.54$ & $36.36 \pm 0.98$ & $35.43 \pm 0.13$ & $34.98 \pm 0.36$ \\
Lactobacillus sp. LB-1 & $36.11 \pm 0.54$ & $39.56 \pm 0.46$ & $42.08 \pm 0.55$ & $44.71 \pm 0.77$ \\
Lactobacillus sp. LB-2 & $36.11 \pm 0.54$ & $39.23 \pm 0.11$ & $41.24 \pm 0.41$ & $38.16 \pm 0.67$ \\
Lactobacillus sp. LB-3 & $36.11 \pm 0.54$ & $41.44 \pm 0.63$ & $43.68 \pm 0.35$ & $41.98 \pm 0.75$ \\
Bacillus sp. BS-1 & $36.11 \pm 0.54$ & $44.56 \pm 0.58$ & $43.71 \pm 0.23$ & $41.96 \pm 0.63$ \\
Bacillus sp. BS-2 & $36.11 \pm 0.54$ & $44.12 \pm 0.31$ & $42.96 \pm 0.45$ & $45.25 \pm 0.16$ \\
Yeast YM-1 & $36.11 \pm 0.54$ & $47.51 \pm 0.16$ & $46.56 \pm 0.39$ & $38.94 \pm 0.46$ \\
Yeast YM-2 & $36.11 \pm 0.54$ & $36.67 \pm 0.21$ & $35.94 \pm 0.07$ & $38.94 \pm 0.86$ \\
Yeast YM-3 & $36.11 \pm 0.54$ & $40.24 \pm 0.09$ & $39.20 \pm 0.75$ & $38.16 \pm 0.24$ \\
\hline
\end{tabular}

Fermentation was carried out at $30^{\circ} \mathrm{C}$.

${ }^{*}$ Phloroglucinol equivalents, ${ }^{\dagger}$ Eisenia bicyclis water extract. 
increased due to microbial fermentation. Peak scavenging activity (about $72 \%$ ) was observed in the extract after one day of fermentation by yeast strain YM-1. However, the DPPH radical-scavenging activity gradually decreased as fermentation progressed. In contrast, a reduction in antioxidant activity was

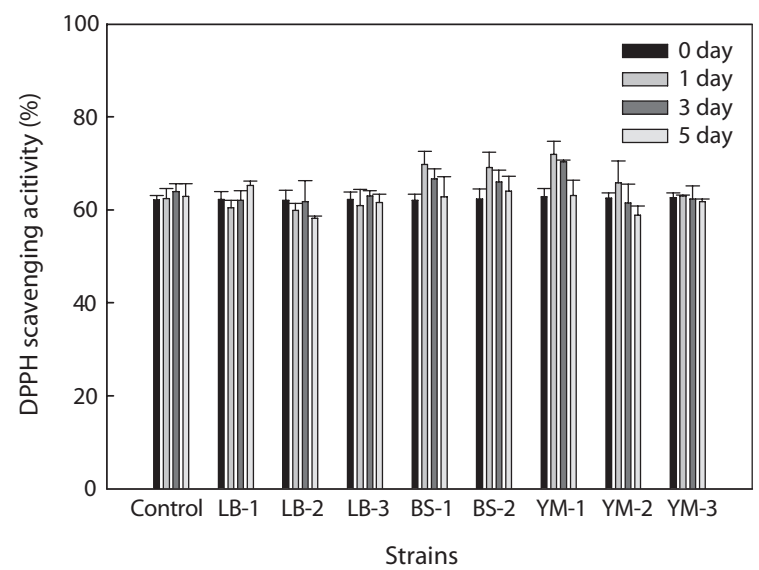

Fig. 1. Effect of microbial fermentation on DPPH radical scavenging activity of Eisenia bicyclis water extract. Experiments were repeated three times. LB-1, LB-2 and LB-3 stand for Lactobacillus sp. LB-1, LB-2 and LB-3, respectively. BS-1 and BS-2 are Bacillus sp. BS- 1 and BS-2, respectively. YM1,2 and 3 are yeast strains isolated in this study.

Table 2. Physiological characteristics of yeast YM-1 strain

\begin{tabular}{|c|c|}
\hline Test & Result \\
\hline D-Glucose & $+^{*}$ \\
\hline Glycerol & + \\
\hline 2-Keto-gluconate & $-\dagger$ \\
\hline L-Arabinose & - \\
\hline D-Xylose & + \\
\hline Adonitol & - \\
\hline Xylitol & - \\
\hline D-Galactose & - \\
\hline Inositol & - \\
\hline D-Sorbitol & - \\
\hline$\alpha$-Methyl-D-glucopyranoside & - \\
\hline N-Acetyl-glucosamine & - \\
\hline D-Cellobiose & + \\
\hline D-Lactose & - \\
\hline D-Maltose & + \\
\hline D-Sucrose & + \\
\hline D-Trehalose & + \\
\hline D-Melezitose & + \\
\hline D-Raffinose & + \\
\hline Identity (\%) & $(94.9 \%)$ \\
\hline
\end{tabular}

The strain was identified based on the analysis of physiological characteristics using the API 20C AUX as described in Materials and Methods.

"Positive reaction, ${ }^{\dagger}$ Negative reaction. observed in the other samples, reflecting the different physiological functions of the enzymes from the other microorganisms (De Mot and Verachtert, 1985; Bar-Shimon et al., 2004). Considering the enhanced TP content and DPPH radical scavenging activity obtained through microbial fermentation, we selected yeast strain YM-1 for our subsequent experiments.

\section{Identification of yeast strain YM-1}

The selected strain (YM-1) was identified based on an analysis of its physiological characteristics and the API Analytical Profile Index as described in the Materials and Methods. The physiological characteristics of the strain are given in Table 2. YM-1 exhibited $94.9 \%$ identity with Candida utilis, and thus we identified the strain as C. utilis. C. utilis is a high proteinyielding species used in food and feed supplements for livestock (Sakata and Kurokawa, 1992). It is also an industrially important microorganism approved by the US Food and Drug Administration as a safe substance (Misawa and Shiamada, 1997).

\section{Physicochemical changes in E. bicyclis extract caused by YM-1 fermentation}

Microbial fermentation causes changes in food constituents (Jeng et al., 2007). Accordingly, it was expected that a change in the properties of E. bicyclis extract would occur during the fermentation of YM-1. As shown in Table 3, no significant difference was observed in the proximate composition (e.g., moisture, crude lipid, crude protein, and crude ash). However, the reducing sugar content decreased gradually as fermentation progressed, suggesting that carbohydrates are used as a substrate for growth of the yeast (Bae and Kim, 2010). In practice, the yeast cells grew gradually until 3 days of fermentation and showed reduced growth thereafter (data not shown). These results are in accordance with our previous data (Eom et al., 2010; Song et al., 2011b). We also found that there was no significant change in $\mathrm{pH}$ or salinity during fermentation (Table 3).

We additionally investigated the effect of fermentation by YM-1 on the FAA content of E. bicyclis extract. In total, 29 FAAs were detected in the control (unfermented) extract. The E. bicyclis extract exhibited large amounts of cysteine, phosphorylated serine, ornithine, and sarcosine compared to the FAA contents of the other seaweed extracts (Table 4). Song et al. (2011b) reported that glutamic acid, alanine, valine, and leucine were the predominant FAAs in an $H$. fusiforme water extract. Furthermore, it was reported that glutamic acid, aspartic acid, and alanine were the predominant FAAs in an $L$. japonica water extract (Eom et al., 2010).

The FAA content was also affected by C. utilis (YM-1) fermentation. A comparison of the FAA content revealed that the total FAA content increased slightly after one day of fermentation and then decreased gradually as fermentation 
Eom et al. (2011) Enhancement of Polyphenol Content of Eisenia bicyclis Extract by Fermentation

Table 3. Change of proximate components, $\mathrm{pH}$ and salinity by Candida utilis YM-1 fermentation in Eisenia bicyclis water extract

\begin{tabular}{lcccc}
\hline & \multicolumn{4}{c}{ Fermentation period (day) } \\
\cline { 2 - 5 } & $\mathbf{0}$ & $\mathbf{1}$ & $\mathbf{3}$ & $\mathbf{5}$ \\
\hline Moisture (\%) & $96.40 \pm 0.02$ & $96.53 \pm 0.01$ & $96.51 \pm 0.05$ & $97.28 \pm 0.06$ \\
Crude protein (\%) & $0.24 \pm 0.04$ & $0.30 \pm 0.05$ & $0.28 \pm 0.03$ & $0.20 \pm 0.01$ \\
Crude lipid (\%) & $0.83 \pm 0.02$ & $0.82 \pm 0.05$ & $0.78 \pm 0.01$ & $0.73 \pm 0.02$ \\
Crude ash (\%) & $0.83 \pm 0.03$ & $0.80 \pm 0.08$ & $0.75 \pm 0.01$ & $0.67 \pm 0.09$ \\
Reducing sugar (\%) & $0.74 \pm 0.02$ & $0.75 \pm 0.01$ & $0.68 \pm 0.01$ & $0.52 \pm 0.01$ \\
pH & $4.09 \pm 0.04$ & $4.11 \pm 0.02$ & $4.16 \pm 0.01$ & $4.33 \pm 0.0 .3$ \\
Salinity (\%) & 2.80 & 2.70 & 2.60 & 2.60 \\
\hline
\end{tabular}

Fermentation was carried out at $30^{\circ} \mathrm{C}$.

Table 4. Effect of Candida utilis YM-1 fermentation on free amino acid content of Eisenia bicyclis water extract

\begin{tabular}{|c|c|c|c|c|}
\hline \multirow{2}{*}{ Free amino acid } & \multicolumn{4}{|c|}{ Fermentation period (day) } \\
\hline & $\mathbf{0}$ & 1 & 3 & 5 \\
\hline Citrulline & 3.60 & $-^{*}$ & 24.57 & 8.12 \\
\hline Cysteine & 475.71 & 403.00 & 294.32 & 23.64 \\
\hline Glutamic acid & 7.46 & 10.84 & 5.78 & 3.59 \\
\hline Taurine & 14.16 & 16.08 & 14.39 & 13.41 \\
\hline Urea & - & 55.79 & - & - \\
\hline Alanine & 0.68 & - & 1.13 & - \\
\hline Cystathionine & 18.77 & 1.89 & 1.62 & - \\
\hline Methionine & 1.57 & 23.99 & - & - \\
\hline Threonine & 32.66 & 16.37 & 17.58 & 2.85 \\
\hline Isoleucine & 1.62 & 3.00 & 2.89 & 1.25 \\
\hline Leucine & 4.79 & 1.62 & 1.45 & 1.01 \\
\hline Tyrosine & 2.14 & 17.20 & 10.67 & 6.27 \\
\hline Phenylalanine & 3.29 & 7.85 & 3.62 & 2.34 \\
\hline g-Aminobutyric acid & - & - & - & 0.15 \\
\hline Ethanolamine & - & 2.12 & 0.59 & 0.14 \\
\hline phosphorylated serine & 130.63 & 148.81 & 140.90 & 155.97 \\
\hline Glycine & - & 0.52 & 0.37 & 0.54 \\
\hline Lysine & - & 3.42 & 2.77 & 1.16 \\
\hline Histidine & 10.98 & - & - & - \\
\hline DL-a-aminoadipic acid & 0.39 & - & - & - \\
\hline a-Amino-n-butyric acid & - & 30.67 & - & - \\
\hline ß-Aminoisobutyric Acid & - & 0.15 & 2.13 & 0.28 \\
\hline Ornithine & 237.04 & 179.67 & 193.20 & 226.31 \\
\hline 1-Methylhistidine & - & 4.30 & 3.51 & 5.92 \\
\hline 3-Methylhistidine & - & 1.03 & 1.20 & 1.30 \\
\hline Sarcosine & 194.57 & 305.56 & 151.97 & 1.94 \\
\hline Anserine & 13.29 & - & - & - \\
\hline Carnosine & - & 4.82 & 3.97 & - \\
\hline Total & 1153.35 & 1238.70 & 878.63 & 456.19 \\
\hline
\end{tabular}

Values are presented as $\mu \mathrm{mol} / 100 \mathrm{~g}$. Fermentation was carried out at $30^{\circ} \mathrm{C}$. "Not determined. progressed (Table 4). Similar to the reducing sugar content, the FAAs appeared to be used as a substrate for yeast growth during fermentation. For example, the phosphorylated serine content, which has proposed anti-obesity effects (Cremades et al., 2004), increased until 5 days of fermentation.

Considering the results obtained in the current study, we conclude that $C$. utilis YM-1 is a good candidate strain for the fermentation of E. bicyclis extracts. Additionally, the TP content, DPPH radical scavenging activity, and FAA content measured in this study strongly indicate that the optimum level of fermentation by strain YM-1 was achieved after one day of fermentation. In this study, we examined the possibility of using fermentation to develop value-added food ingredients from E. bicyclis. Microbial fermentation by C. utilis YM-1 resulted in enhanced biological activity, including an increased TP content and antioxidant activity, suggesting that $C$. utilis YM-1 fermentation is an attractive strategy for developing value-added food ingredients.

\section{Acknowledgments}

This research was supported by the special fund of Pukyong National University donated by the SKS Trading Co. in Lynnwood, Washington, USA in memory of late Mr. Young Hwan Kang, who had a deep concerns and inspiration in fishery science.

\section{References}

Achinewhu SC, Barber LI and Ijeoma IO. 1998. Physicochemical properties and garification (gari yield) of selected cassava cultivars in Rivers State, Nigeria. Plant Foods Hum Nutr 52, 133-140.

Adewusi SRA, Ojumu TV and Falade OS. 1999. The effect of processing on total organic acids content and mineral availability of simulated cassava-vegetable diets. Plant Foods Hum Nutr 53, 367-380. Association of Official Analytical Chemicals. 1995. Official Methods of 
Anaylsis. 16th ed. Association of Official Analytical Chemicals, Washington, DC, US, pp. 49-59.

Athukorala Y, Kim KN and Jeon YJ. 2006. Antiproliferative and antioxidant properties of an enzymatic hydrolysate from brown alga, Ecklonia cava. Food Chem Toxicol 44, 1065-1074.

Bae HN and Kim YM. 2010. Improvement of the functional qualities of sea tangle extract through fermentation by Aspergillus oryzae. Fish Aquat Sci 13, 12-17.

Bar-Shimon M, Yehuda H, Cohen L, Weiss B, Kobeshnikov A, Daus A, Goldway M, Wisniewski M and Droby S. 2004. Characterization of extracellular lytic enzymes produced by the yeast biocontrol agent Candida oleophila. Curr Genet 45, 140-148.

Cremades A, Ruzafa C, Monserrat F, López-Contreras AJ and Peñafiel R. 2004. Influence of dietary arginine on the anabolic effects of androgens. J Endocrinol 183, 343-351.

De Mot R and Verachtert H. 1985. Purification and characterization of extracellular amylolytic enzymes from the yeast Filobasidium capsuligenum. Appl Environ Microbiol 50, 1474-1482.

Eom SH, Lee BJ and Kim YM. 2010. Effect of yeast fermentation on the antioxidant and anti-inflammatory activity of sea tangle water extract. Kor J Fish Aquat Sci 43, 117-124.

Fenn JP, Segal H, Barland B, Denton B, Whisenant J, Chun H, Christofferson K, Hamilton L and Carroll K. 1994. Comparison of updated Vitek Yeast Biochemical Card and API 20C yeast identification systems. J Clin Microbiol 32, 1184-1187.

Gündeş SG, Gulenc S and Bingol R. 2001. Comparative performance of Fungichrom I, Candifast and API 20C Aux systems in the identification of clinically significant yeasts. J Med Microbiol 50, 11051110.

Heo SJ and Jeon YJ. 2005. Antioxidant effect and protecting effect against cell damage by enzymatic hydrolysates from marine algae. Food Ind Nutr 10, 31-41.

Heo SJ, Park EJ, Lee KW and Jeon YJ. 2005. Antioxidant activities of enzymatic extracts from brown seaweeds. Bioresour Technol 96, 1613-1623.

Jeng KC, Chen CS, Fang YP, Hou RC and Chen YS. 2007. Effect of microbial fermentation on content of statin, GABA, and polyphenols in Pu-Erh tea. J Agric Food Chem 55, 8787-8792.

Jiménez-Escrig A, Jiménez-Jiménez I, Pulido R and Saura-Calixto F. 2001. Antioxidant activity of fresh and processed edible seaweeds. J Sci Food Agric 81, 530-534.

Jung HA, Oh SH and Choi JS. 2010. Molecular docking studies of phlorotannins from Eisenia bicyclis with BACE1 inhibitory activity. Bioorg Med Chem Lett 20, 3211-3215.

Kim KH, Tsao R, Yang R and Cui SW. 2006a. Phenolic acid profiles and antioxidant activities of wheat bran extracts and the effect of hydrolysis conditions. Food Chem 95, 466-473.

Kim KN, Heo SJ, Song CB, Lee J, Heo MS, Yeo IK, Kang KA, Hyun
JW and Jeon YJ. 2006b. Protective effect of Ecklonia cava enzymatic extracts on hydrogen peroxide-induced cell damage. Process Biochem 41, 2393-2401.

Lee SH, Yong-Li, Karadeniz F, Kim MM and Kim SK. 2009. $\alpha$-Glucosidase and $\alpha$-amylase inhibitory activities of phloroglucinol derivatives from edible marine brown alga, Ecklonia cava. $\mathrm{J}$ Sci Food Agric 89, 1552-1558.

Maegawa M. 1990. Ecological studies of Eisenia bicyclis (Kjellma) Setchell and Ecklonia cava Kjellman. Bull Fac Bioresour Mie Univ 4, 73-145.

McDougall GJ, Shpiro F, Dobson P, Smith P, Blake A and Stewart D. 2005. Different polyphenolic components of soft fruits inhibit $\alpha$-amylase and $\alpha$-glucosidase. J Agric Food Chem 53, 2760-2766.

Misawa N and Shiamada H. 1997. Metabolic engineering for the production of carotenoids in non-carotenogenic bacteria and yeasts. J Biotechnol 59, 169-181.

Nagayama K, Iwamura Y, Shibata T, Hirayama I and Nakamura T. 2002. Bactericidal activity of phlorotannins from the brown alga Ecklonia kurome. J Antimicrob Chemother 50, 889-893.

Noda H, Amano H, Arashima K, Hashimoto S and Nisizawa K. 1989. Studies on the antitumour activity of marine algae. Nippon Suisan Gakkaishi 55, 1259-1264.

Okada Y, Ishimaru A, Suzuki R and Okuyama T. 2004. A new phloroglucinol derivative from the brown alga Eisenia bicyclis: potential for the effective treatment of diabetic complications. J Nat Prod 67, 103-105.

Qureshi MN, Kuchekar BS, Logade NA and Haleem MA. 2010. In-vitro antioxidant and in-vivo hepatoprotective activity of Leucas ciliata leaves. Rec Nat Prod 4, 124-130.

Sakata T and Kurokawa M. 1992. Feeding modulation by pentose and hexose analogues. Am J Clin Nutr 55(1 Suppl), 272S-277S.

Shibata T, Fujimoto K, Nagayama K, Yamaguchi K and Nakamura T. 2002. Inhibitory activity of brown algal phlorotannins against hyaluronidase. Int J Food Sci Technol 37, 703-709.

Shibata T, Nagayama K, Tanaka R, Yamaguchi K and Nakamura T. 2003. Inhibitory effects of brown algal phlorotannins on secretory phospholipase $\mathrm{A}_{2} \mathrm{~s}$, lipoxygenases and cyclooxygenases. J Appl Phycol 15, 61-66.

Somogyi M. 1952. Notes on sugar determination. J Biol Chem 195, 1923.

Song HS, Eom SH, Kang YM, Choi JD and Kim YM. 2011a. Enhancement of the antioxidant and anti-inflammatory activity of Hizikia fusiforme water extract by lactic acid bacteria fermentation. Korean J Fish Aquat Sci 44, 111-117.

Song HS, Kim HK, Min HO, Choi JD and Kim YM. 2011b. Changes in physicochemical and sensory properties of Hizikia fusiforme water extract by fermentation of lactic acid bacteria. Korean J Fish Aquat Sci 44, 104-110. 